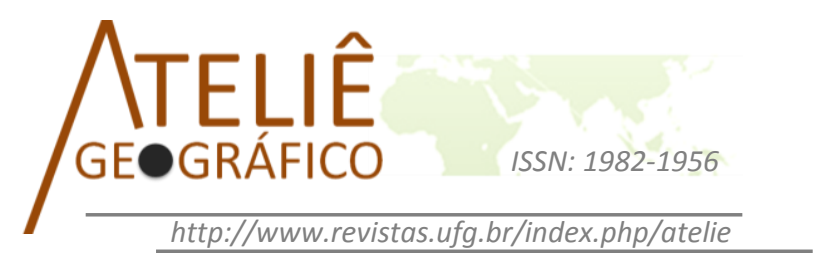

\title{
Inter-relações entre a frota de veículos, a ocorrência de acidentes de trânsito e o adensamento populacional no Espírito Santo
}

\author{
Interrelation among vehicle fleet, population density and \\ traffic accidents in Espirito Santo
}

\section{Interrelaciones entre la flota de vehículos, la ocurrencia de accidentes de tránsito el adensamento poblacional en el Espirito Santo}

\author{
Aurélia Hermínia Castiglioni \\ Universidade Federal do Espírito Santo \\ aurélia.castiglioni@gmail.com \\ Maria Inês Faé \\ Universidade Federal do Espírito Santo \\ mariafae@gmail.com
}

\begin{abstract}
Resumo
$\mathrm{O}$ artigo tem por objetivo analisar a distribuição espacial e as relações entre o tamanho da frota de veículos e da população e a ocorrência de acidentes de trânsito no Espírito Santo. O aumento no número de veículos no Brasil tem sido elevado, superando o crescimento demográfico e da urbanização. Porém, a capacidade de expansão e de modernização da rede viária não consegue acompanhar o ritmo de crescimento da frota. Uma das consequências desta defasagem é traduzida pelo aumento de acidentes, cujos índices colocam o Brasil entre os países com as mais elevadas taxas de ocorrência de acidentes e de mortes no trânsito. As associações existentes entre a distribuição da frota, da população e a ocorrência dos acidentes e das vítimas no Espírito Santo são analisadas por meio da aplicação de métodos estatísticos para análise dos dados. Os resultados mostram forte correlação entre as variáveis analisadas. A espacialização dessas associações oferece um claro cenário dos contrastes entre os municípios do Espírito Santo onde os maiores índices de acidentes ocorrem onde há maiores densidades populacionais e maiores frotas, particularmente na Região Metropolitana da Grande Vitória. As regiões do norte e do oeste do estado apresentam menor ocorrência de acidentes.
\end{abstract}

Palavras-chave: acidentes de trânsito, vítimas de acidentes de trânsito, frota de veículos, distribuição da população. 


\begin{abstract}
The article aims to analyze the spatial distribution and the relationship between the size of the vehicle fleet and the population and the occurrence of traffic accidents in Espirito Santo. The increase in the number of vehicles in circulation in Brazil has been high, exceeding population and urbanization growth. Capacity expansion and modernization of the road network has not been aligned with the fleet increases. A consequence of this gap is shown in traffic accident increases whose indices put Brazil among the countries with the highest rates of accidents and traffic deaths. The relation among fleet distribution, population, and the occurrence of accidents and victims in Espirito Santo are analyzed by statistical methods of data analysis. The results show a strong correlation between the variables. The spatial distribution of the variables highlights the contrasts among the municipalities of Espirito Santo, where the highest rates of accidents occur with high population densities and large fleets, particularly in the metropolitan area of Greater Victoria. North and West regions have low accident levels.
\end{abstract}

Keywords: traffic accident; traffic casualties; vehicle fleet; population distribution.

\begin{abstract}
Resumen
Este artículo tiene como objetivo analizar la distribución espacial y las relaciones entre el tamaño de la flota de vehículos y de población y la ocurrencia de accidentes de tránsito en Espirito Santo. El aumento del número de vehículos en Brasil ha sido elevado, superando el crecimiento demográfico y urbanístico. No obstante, la capacidad de expansión y de modernización de la red vial no consigue acompañar el ritmo de crecimiento de la flota. Una de las consecuencias de este descompás se traduce en el aumento de accidentes, cuyos índices colocan Brasil entre los países con las más elevadas tasas de ocurrencias de accidentes y muertes en el tránsito. Las asociaciones existentes entre la distribución de la flota, de la población y la ocurrencia de accidentes y víctimas en Espirito Santo son analizadas a través de la aplicación de métodos estadísticos para análisis de los datos. Los resultados muestran una fuerte relación entre las variables analizadas. La distribución espacial de estas asociaciones muestra un claro escenario de los contrastes existentes entre los municipios de Espirito Santo donde los mayores índices de accidentes ocurren donde hay mayor densidad demográfica y mayor flota de vehículos, especialmente en la región metropolitana de Grande Vitória. Las regiones del norte y del oeste presentan menores ocurrencias de accidentes.
\end{abstract}

Palabras clave: accidentes de tránsito, víctimas de accidentes de tránsito, flota de vehículos, distribución de la población.

\title{
Introdução
}

A frota mundial de veículos já ultrapassou a marca de 1 bilhão de veículos e no cenário internacional os países emergentes ganham progressivamente mais espaço, devido ao crescimento de suas economias e do poder aquisitivo de suas populações. Segundo o Departamento Nacional de Trânsito - DENATRAN (MINISTÉRIO DAS CIDADES, acesso em: 05/12/2013), o número de veículos registrados do Brasil atingiu 64.817.974 veículos em dezembro de 2010, o que significa um aumento acumulado de $118,1 \%$ entre 2000 e 2010 . De 2011 a 2013 a frota nacional cresceu em quase 17 milhões de veículos $(25,9 \%)$ (MINISTÉRIO DAS CIDADES, acesso em: 03/02/2014). 
$\mathrm{O}$ ritmo do crescimento da frota supera o da população. Enquanto a frota apresenta tendência de crescimento progressivo, os padrões demográficos apresentaram transformações expressivas em todo o Brasil, particularmente na segunda metade do século XX, resultantes da evolução conjunta dos processos de transição demográfica, de transição epidemiológica e de urbanização.

A transição demográfica é caracterizada por declínios diferenciais das componentes do crescimento natural, a mortalidade, cuja queda dá início ao processo, e a fecundidade, que declina mais tarde, com consequências sobre o crescimento demográfico e sobre a estrutura etária da população (LANDRY, 1934; PATARRA; FERREIRA, 1996). Atualmente o país vivencia a fase da transição caracterizada pela redução do crescimento, aproximando-se do final do processo, quando natalidade e mortalidade tendem a apresentar níveis baixos, próximos, o que resulta em crescimento baixo ou mesmo negativo. Paralelamente, ocorrem mudanças na composição da mortalidade: as doenças infecciosas e parasitárias, principais causas de óbitos no início das transições demográfica e epidemiológica, declinam e as doenças crônico-degenerativas passam a ocupar o topo do ranking das causas de mortalidade, acompanhadas pelo Grupo de Causas Externas, que inclui as mortes por acidentes de trânsito (SCHRAMM et al, 2004).

As mudanças demográficas são também observadas na migração, a outra componente do crescimento demográfico, em especial a rural-urbana, cuja intensidade modificou fortemente a distribuição da população do Brasil na segunda metade do século XX. As consequências principais da redistribuição da população foram a urbanização rápida e a forte concentração da população nos principais centros urbanos.

O crescimento da frota de veículos em circulação, o crescimento demográfico, o aumento da mobilidade exercem pressão sobre a oferta e modernização da infraestrutura de transportes. No entanto, o que tem ocorrido é a defasagem crescente entre crescimento urbano e da frota de veículos com relação aos investimentos realizados para expansão e modernização da rede viária, provocando a lentidão do fluxo, os engarrafamentos, o mau estado das vias e da sinalização, o aumento das emissões atmosféricas e do ruído, dentre outros. Devido ao elevado incremento da urbanização na segunda metade do século XX, os sistemas de mobilidade das aglomerações urbanas passaram a operar com baixa qualidade e com altos custos para a sociedade (VASCONCELLOS; CARVALHO; PEREIRA, 2011). A administração pública não tem se mostrado capacitada para solucionar os problemas do trânsito e do transporte coletivo nas metrópoles. No artigo sobre a ocorrência de acidentes de trânsito em Uberlândia, Alves e Raia Júnior ressaltam que o crescimento populacional urbano associado ao aumento dos veículos 
individuais, especialmente de automóveis e motocicletas, promovem "alterações na operação e gestão do sistema viário que passa a ser pensado e planejado, de forma prioritária, para atender ao transporte motorizado individual em detrimento dos modos não motorizados e do transporte público" (ALVES; RAIA JÚNIOR, 2012, p. 55, acesso em 12/12/2013).

O efeito mais grave deste descompasso é traduzido pelo número crescente de acidentes de trânsito, muitos deles com vítimas fatais. As estatísticas do Sistema de Informação Sobre Mortalidade - SIM, do Ministério da Saúde apontam 43.908 óbitos decorrentes de acidentes de transportes terrestres ocorridos no país em 2010. O perfil típico destas vítimas é de um jovem do sexo masculino: $81,6 \%$ das vítimas fatais são homens e $45,1 \%$ das vítimas têm entre 15 e 35 anos (MINISTÉRIO DA SAÚDE - SIM, acesso em 08/12/2013).

O Brasil ocupa a quinta posição em número de acidentes de trânsito, atrás da Índia, China, Estados Unidos e Rússia (EMPRESA BRASIL DE COMUNICAÇÃO, acesso em 12/12/2013). Para ilustrar a continuidade desse cenário, no ano de 2013, o pagamento de seguros de danos pessoais causados por veículos automotores de vias terrestres (DPVAT) cresceu em 25\%. Esse benefício garante a indenização em caso de acidente de trânsito que resulte em morte ou invalidez permanente e o reembolso de despesas médicas e hospitalares. Embora o veículo motocicleta represente apenas $27 \%$ da frota nacional, $71 \%$ da demanda do seguro DPVAT foi atribuído a esse veículo, seguida de automóveis que responderam por $24 \%$ dos indenizados (AGÊNCIA CNT DE NOTÍCIAS, acesso em: 14/02/2014).

Este estudo, que focaliza o Estado do Espírito Santo, tem por objetivos: (1) analisar a evolução e a distribuição da frota de veículos, da população, o número e a composição dos acidentes de trânsito e as vítimas provocadas por acidentes no Estado do Espírito Santo; (2) caracterizar e sintetizar as interrelações existentes entre esses processos; (3) formar grupos de municípios que apresentam similaridades quanto às características dos processos considerados e aos níveis dos seus indicadores.

Embora seja o terceiro menor estado em área, o Espírito Santo aparece em $11^{\circ}$ lugar dentre as 27 Unidades Administrativas que compõem o país, com 1.262.848 veículos no ano de 2010 (MINISTÉRIO DAS CIDADES, acesso em: 05/12/2013). O crescimento dessa frota no período de 2000 a 2010 $(149,7 \%)$ foi maior que o crescimento médio observado no Brasil $(118,1 \%)$ e também maior que o de São Paulo e o da Região Sudeste $(98,5 \%)$. Ou seja, o Espírito Santo apresentou expansão superior a da Região mais desenvolvida do país, na qual se localiza (CASTIGLIONI; FAÉ, 2012). Em 2013 a frota do Espírito Santo atingiu 1.585.076 veículos (MINISTÉRIO DAS CIDADES, 
acesso em: 03/02/2014). No período compreendido entre 2011 e 2013, o estado do Espírito Santo teve um aumento de frota de $25,5 \%$ enquanto que São Paulo teve 19,6\%. O número de veículos colocados em circulação no Espírito Santo teve um impacto significativo em sua infraestrutura considerando a pequena área territorial e o reduzido comprimento do sistema viário quando comparado ao de São Paulo. A frota de veículos concentra-se nas principais cidades, onde é registrada a maior incidência de acidentes e de vítimas de trânsito.

Os indicadores utilizados foram construídos com dados publicados pelas fontes: DETRAN-ES - Departamento Estadual de Trânsito, para a frota, acidentes e vítimas, IBGE - Instituto Brasileiro de Geografia e Estatística, para a População, SIM - Sistema de Informações sobre Mortalidade, do Ministério de Saúde, para caracterizar os óbitos provocados por acidentes de transportes.

Os dados utilizados no presente estudo apresentam limitações, sobretudo no que concerne à disponibilidade de dados de transportes e de acidentes desagregados em nível municipal, o que limitou o período de análise. Os dados disponíveis, mais detalhados para os últimos anos, por outro lado, forneceram as informações necessárias para a busca dos objetivos propostos.

\section{Caracterização dos padrões demográficos}

O Espírito passou por transformações importantes durante a segunda metade do século XX, decorrentes da mudança da estrutura do sistema produtivo, de economia agrária para as atividades urbano-industriais. Nas primeiras décadas deste período o Estado passou por uma fase caracterizada por crescimento demográfico acelerado, intensa migração rural-urbana e concentração da população na Região Metropolitana da Grande Vitória RMGV, formada pelos municípios de Cariacica, Fundão, Guarapari, Serra, Viana, Vila Velha e Vitória. Atualmente o Estado encontra-se em uma nova etapa, de desaceleração do crescimento natural, dos movimentos rural-urbanos e do crescimento da principal aglomeração urbana. A taxa de urbanização continua a crescer, embora mais lentamente que nas décadas de 1970 e 1980, e seu ritmo de crescimento continua superior ao do Estado (CASTIGLIONI, 2009). Mudaram os padrões da mobilidade, com diminuição da migração ruralurbana e intensificação da migração interurbana e dos deslocamentos interurbanos para trabalho e estudo, em especial entre os municípios da RMGV e nas principais cidades.

A população do Espírito Santo passou de 861.562 habitantes em 1950 à 3.514 .952 em 2010 (IBGE, 1955, 2011, acesso em: 15/11/2013). Concomitantemente ao crescimento demográfico a segunda metade do século XX foi marcada por uma importante redistribuição da população no Estado. 
Em 1950 o Espírito Santo era um dos estados mais rurais do país: a população urbana representava apenas $20,8 \%$ da população total. Na década de 1970 o estado passou a ser predominantemente urbano, e, a seguir, o indicador de urbanização subiu para 79,5\% em 2000 e ainda para 83,4\% em 2010 (IBGE 1955, 2001, 2011, acesso em :15/11/2013). Os investimentos efetuados na segunda metade do século XX privilegiaram as atividades industriais, comerciais e serviços, que se estabeleceram majoritariamente na região da capital.

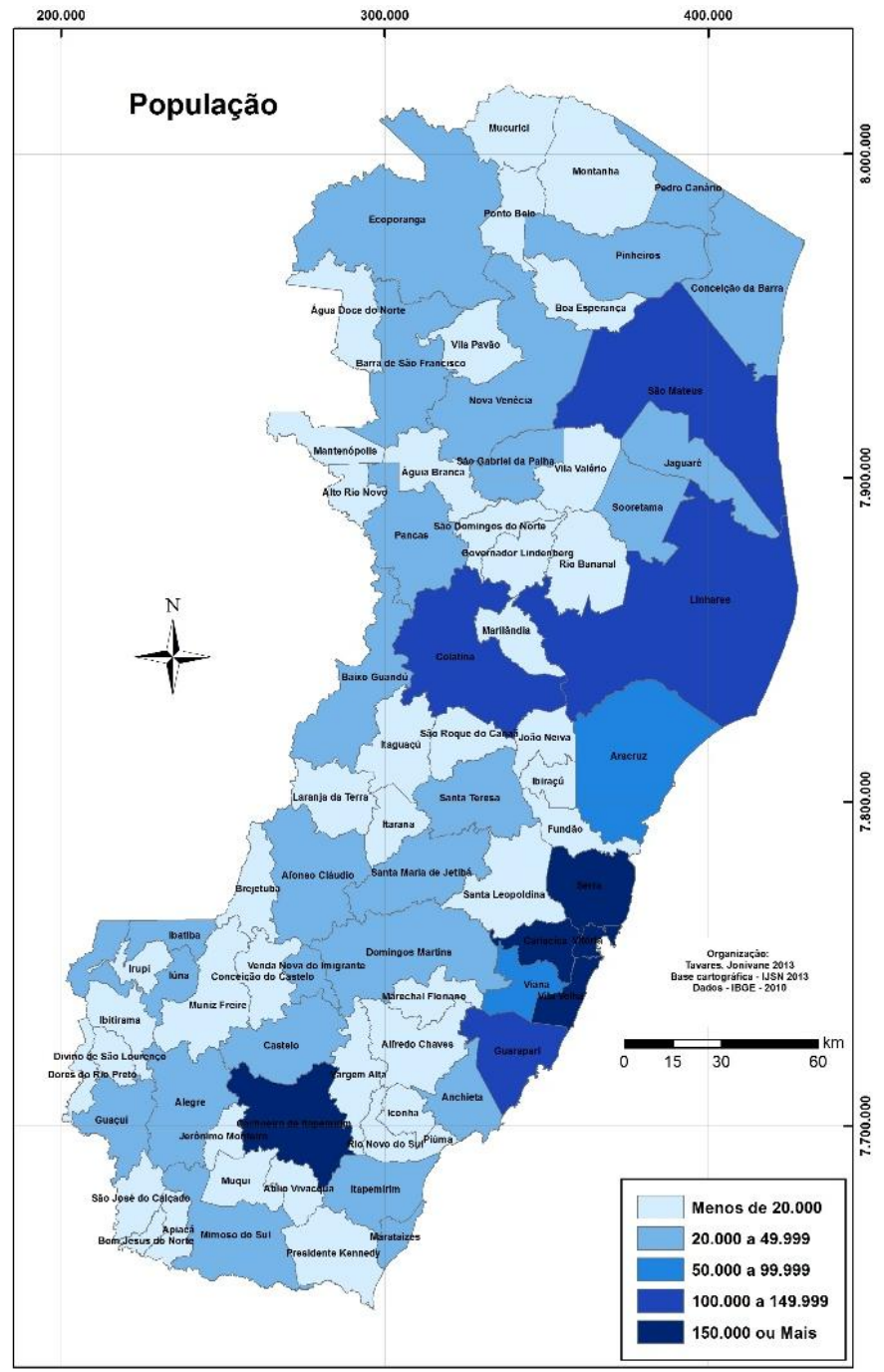

Figura 1: Distribuição da População - Espírito Santo ( 2010) 
A população se distribui desigualmente pelos 78 municípios do Estado (Figura 1), concentrando-se na faixa próxima ao litoral, onde se situa a maior aglomeração urbana, a RMGV, em particular nos municípios de Vila Velha, Serra, Cariacica, Vitória e Guarapari. Fora desta região os maiores números, acima de 100.000 habitantes, são encontrados nos dois principais centros urbanos interioranos, Cachoeiro de Itapemirim e Colatina e, no litoral norte, onde as atividades de produção de celulose e da exploração de petróleo promoveram o crescimento dos municípios de Linhares e São Mateus.

Os maiores adensamentos populacionais registram-se em torno de dois polos, nas regiões em torno da capital e de Cachoeiro de Itapemirim. A região sul apresenta-se historicamente mais povoada, pois nela se iniciou o processo de colonização e de povoamento do estado, enquanto que a Região norte, de povoamento mais tardio, apresenta as mais baixas densidades.

O traço marcante da distribuição da população no Espírito Santo é a concentração demográfica progressiva na RMGV. Nos meados do século XX, viviam nesta região $15,3 \%$ da população do Estado, pois a maioria residia nas áreas rurais, onde predominava a cafeicultura, então o pilar da economia do estado. Nas décadas seguintes o intenso êxodo rural drenou progressivamente a população do interior para a região da capital que, em 2010, já concentrava quase a metade da população do Estado (48\%) (IBGE, 1955, 2011, acesso em: $15 / 11 / 2013)$.

\section{Distribuição espacial da frota e dos acidentes de trânsito}

$\mathrm{O}$ indicador que relaciona número de veículos e habitantes mostra que a relação cresceu mais no Espírito Santo que no conjunto do país. Em 2000 o país contava com 1 veículo por 5,7 habitantes, em 2010, a relação era de 2,9; no Espírito Santo, esta relação passou de 1 veículo para 6,1 habitantes em 2000 à 1 veículo para 2,8 habitantes em 2010 (MINISTÉRIO DAS CIDADES, acesso em: 05/12/2013, IBGE, 2001 e 2011, acesso em 15/11/2013).

Na composição da frota do Espírito Santo em 2010 (Figura 2), mais da metade dos veículos é composta por automóveis, seguidos em importância pelas motos e caminhonetes. Os dados da evolução recente colocam em evidência o crescimento fortemente diferenciado dos tipos de veículos. Segundo os dados analisados (DETRAN-ES, 2011), no período de 2005 a 2010, o maior crescimento foi apresentado pelas motos, cujo número quase dobrou (crescimento de 97,6\%), vindo a seguir os automóveis (46,8\%) e caminhonetes e caminhonetas $(36,9 \%)$. 


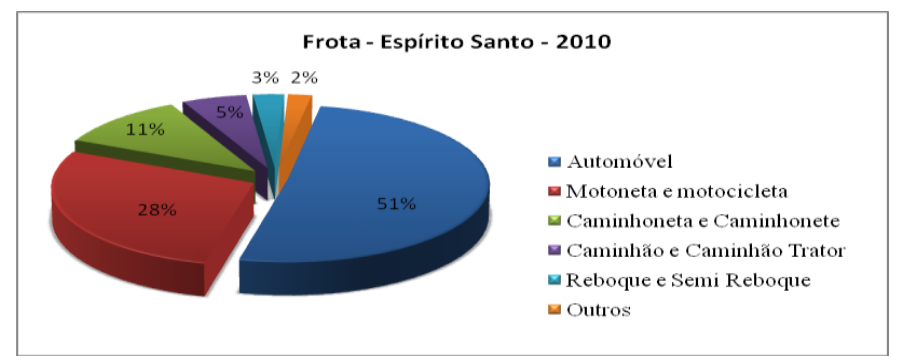

Figura 2: Distribuição da Frota de veículos por tipo - ES (2010) Fonte: organizado com dados do DETRAN - ES, 2011

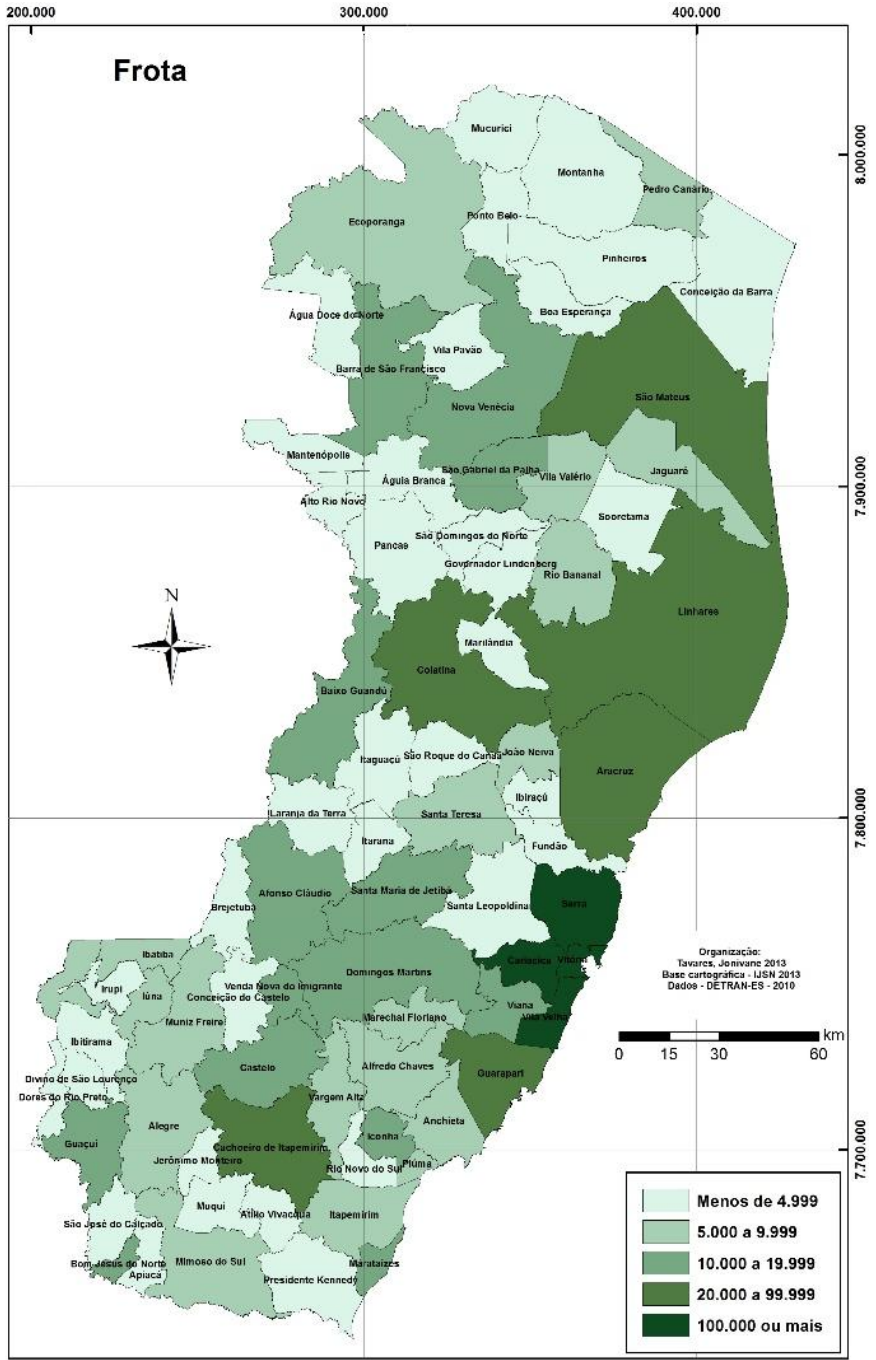

Figura 3: Distribuição espacial da frota - Espírito Santo - 2010 
A distribuição espacial da frota no Espírito Santo, em 2010, apresentada na Figura 3, mostra que os municípios mais populosos da região da capital, Vitória, Vila Velha, Serra e Cariacica apresentam cada um, frota superior a 100.000 veículos. Este grupo congrega 43,1\% do total de veículos do Estado. Segue, em importância numérica, o grupo formado por municípios com frotas entre 20.000 a 80.000. Este grupo agrega as principais cidades da região interiorana, Cachoeiro de Itapemirim no sul e Colatina, no centro-oeste; municípios do litoral norte: Linhares, São Mateus e Aracruz e, na RMVG, o balneário de Guarapari. Os municípios pouco povoados situados no norte e no oeste do Estado contam com pequenas frotas.

As estatísticas das rodovias federais de 2010 fornecem o panorama do trânsito no Espírito Santo. Este estado é o quarto menor em extensão do país e o $14^{\circ}$ em população, conta com apenas $1,3 \%$ da rede rodoviária federal policiada, mas ocupou, em 2010, a oitava posição no ranking de ocorrência de acidentes de trânsito, com 4,3\% dos casos. O Estado é o sétimo do país em número de pessoas envolvidas nos acidentes $(5,1 \%)$ e o décimo em vítimas fatais (3,7\%). (DNIT; DPRF, 2010).

A ocorrência de acidentes segundo os municípios do Espírito Santo é apresentada na Figura 4. Os acidentes estão fortemente concentrados nos municípios mais populosos da RMGV, Vitória, Vila Velha, Serra e Cariacica, em ordem de ocorrências. Nesses quatro municípios concentraram-se 52,5\% do total de acidentes registrados no Estado em 2010. Também para esta variável, os centros urbanos mais populosos fora da RMGV, Cachoeiro de Itapemirim, Linhares, Guarapari, Colatina e São Mateus, aparecem como o segundo grupo em ocorrências, congregando $20,8 \%$ do total de casos. Observa-se, nas distribuições apresentadas, a estreita correlação espacial existente entre $o$ tamanho da população e da frota e a ocorrência de acidentes. 


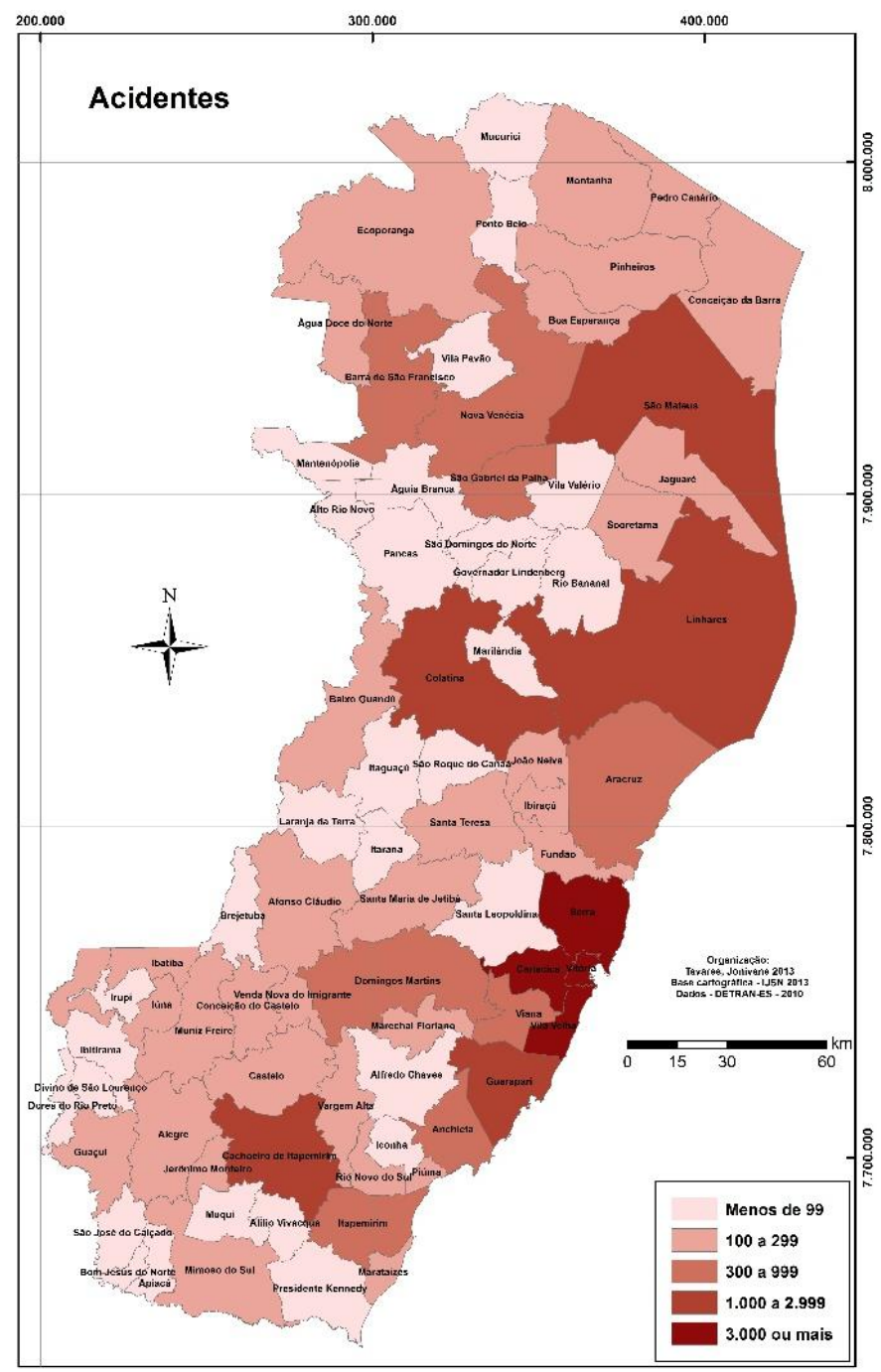

Figura 4: Distribuição espacial dos acidentes de trânsito - Espírito Santo -2010

O DNIT - Departamento Nacional de Infraestrutura de Transportes e o DPRF - Departamento de Polícia Rodoviária Federal definem acidente de trânsito como a "ocorrência fortuita ou não, em decorrência do envolvimento em proporções variáveis do homem, do veículo, da via e demais elementos circunstanciais, da qual tenha resultado ferimento, dano, estrago, avaria, ruína etc." (DNIT; DPRF, 2010, P. 23). Quanto à gravidade, os acidentes são classificados em: (1) acidentes com vítimas, que se subdividem em acidente com morto (evento no qual tenha ocorrido, pelo menos, uma morte, 
independentemente da quantidade de pessoas e de veículos envolvidos) e acidente com ferido (quando há, pelo menos, um ferido com lesões leves ou graves) e (2) acidente sem vítima (todas as pessoas envolvidas apresentam ausência de lesões).

\section{Vítimas de acidentes de trânsito}

Segundo os dados sobre acidentes no período de 2005 a 2010 (DETRAN-ES, acesso em: 10/12/2013; DETRAN-ES, 2011), o número de acidentes de trânsito no Espírito Santo cresceu 42,4\%, passando de 32.528 a 46.309. No período considerado, o crescimento do número de acidentes com vítimas foi de 49,8\% e o de pessoas vitimadas, atingiu 47,0\% (Figura 5). O índice de acidentes com vítimas no quinquênio passou de 296,2 acidentes por 100.000 habitantes em 2005 a 430,4 em 2010.

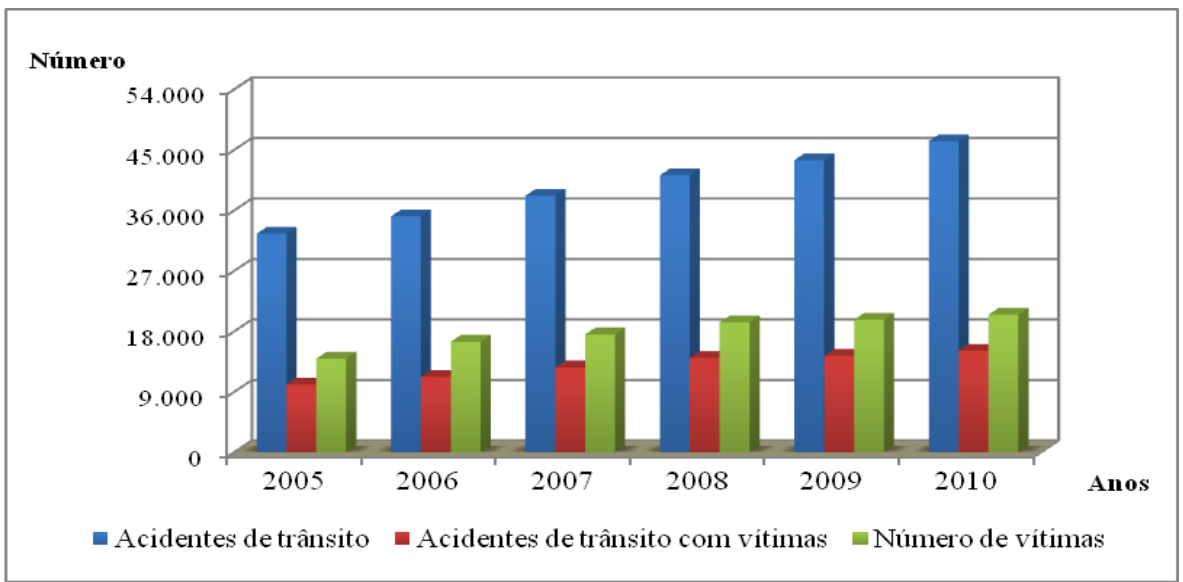

Figura 5: Acidentes de trânsito e vítimas - Espírito Santo - 2005 a 2010

Fonte: Elaborado com dados do DETRAN-ES, acesso em: 10/12/2013; DETRAN-ES, 2011.

Em 2010, cerca de um terço dos acidentes provocaram vítimas (32,7\%). Os 15.120 acidentes com vítimas ocorridos no Espírito Santo atingiram 20.488 pessoas das quais 678 foram vítimas fatais (DETRAN-ES, 2011). A maior parte dos acidentes com vítimas $(60,7 \%)$ ocorre durante o dia, e a maior frequência de casos concentra-se nos fins de semana, nos sábados e domingos ocorreram $34,8 \%$ dos acidentes de 2010.

O perfil dos acidentados traduz a seletividade dos acidentes de trânsito com relação ao gênero e à idade, $74,2 \%$ das vítimas são do sexo masculino, o percentual se eleva a $81,6 \%$ para os acidentes com vítimas fatais (Figura 6). A 
razão de sexo das vítimas de acidentes de trânsito foi de 288,3 mortes masculinas por 100 femininas em 2010; quando se considera os acidentes com vítimas fatais a razão de sexo sobe para 443,5 óbitos masculinos por 100 femininos. As vítimas são majoritariamente jovens, 45,2\% dentre os que declararam a idade têm entre 18 a 29 anos. Estes traços, observados em todo o país, constituem grandes desafios para toda a sociedade, têm requerido e requerem a atenção especial das políticas públicas e sociais.

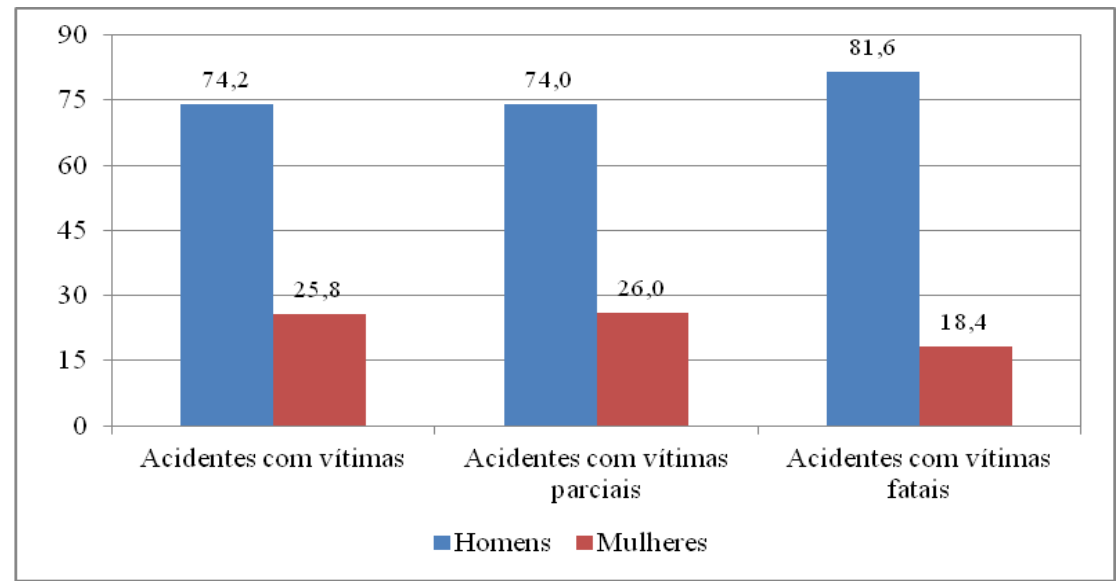

Figura 6: Acidentes de trânsito com vítimas - Espírito Santo - 2010

Fonte: Elaborado com dados do DETRAN-ES, 2011.

A maioria dos acidentes com vítimas ocorre por colisões/abalroamentos $(57,2 \%$ das ocorrências $)$, seguidos pelos trombamentos/capotamentos (11,5\%) e pelos atropelamentos $(11,2 \%)$ (DETRAN-ES, 2011).

Os veículos envolvidos em acidentes com vítimas no Espírito Santo são majoritariamente motocicletas $(39,2 \%)$, vindo a seguir os automóveis e caminhonetas $(38,0 \%)$. Estas duas espécies representam 77,2\% dos casos, com um total de 9.915 acidentes envolvendo motos e 9.612 com automóveis e camionetas (DETRAN-ES, 2011). A representação dos acidentes com vítimas envolvendo motocicletas e as tendências recentes deste quadro constituem um problema grave, cada vez mais presente no trânsito tanto nas grandes aglomerações urbanas como no interior do Estado. No curto período de 2005 a 2010 o número de veículos envolvidos em acidentes com vítimas teve um aumento de 50,3\%. O que mais chama atenção neste quadro é a evolução da participação das espécies de veículos: o número de automóveis e caminhonetas, historicamente os mais numerosos, cresceu $25,9 \%$ no período enquanto que os acidentes envolvendo motocicletas quase dobraram, apresentando um 
crescimento de $98,8 \%$ e colocando esta espécie no topo do ranking de ocorrências em 2010 (Figura 7). A tendência de crescimento das motos tende a acentuar-se por ser este um tipo de veículo de preço mais acessível para o crescente mercado consumidor formado pela parcela da população brasileira de menor renda, que tem elevado seu poder aquisitivo com consequente ampliação no consumo de bens e serviços.

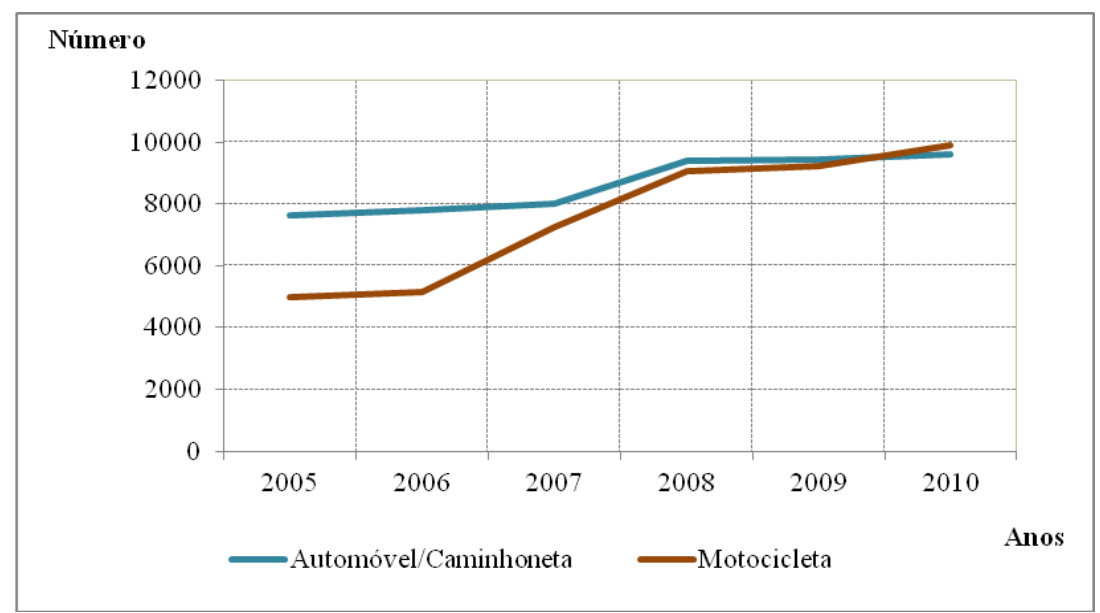

Figura 7: Evolução do número de Acidentes de Trânsito com vítimas envolvendo automóveis/caminhonetas e motocicletas - ES - 2005 a 2010 Fonte: Elaborado com dados do DETRAN-ES; DETRAN-ES, 2011

As estatísticas sobre os tipos de vítimas dos acidentes de trânsito (DETRAN-ES, 2011) fornecem informações, classificadas em vítimas parciais (não fatais) e fatais. Segundo esta fonte foram registradas 678 vítimas fatais em acidentes ocorridos nas estradas e rodovias do Estado em 2010. A evolução do coeficiente de vítimas fatais por 100.000 habitantes mostra o agravamento das condições do trânsito: o valor do indicador subiu de 15,6 para 19,3 vítimas fatais por 100.000 entre 2005 e 2010.

A distribuição espacial dos acidentes com vítimas e dos acidentes com vítimas fatais no Espírito Santo em 2010 apresenta relações com as variáveis já analisadas, relativas ao adensamento da população, ao tamanho da frota e à ocorrência de acidentes.

O número de vítimas de acidentes é maior nos municípios mais populosos da RMGV, Vitória, Vila Velha, Serra e Cariacica, no sul, em Cachoeiro de Itapemirim e, no norte, em Linhares (Figura 8). Os acidentes com vítimas fatais são mais frequentes nos municípios da RMGV: Serra ocupa a primeira posição no Estado, seguido por Vila Velha, Cariacica e Guarapari. No 
grupo dos municípios com maiores números de vítimas fatais incluem-se Cachoeiro de Itapemirim, Linhares, Colatina e São Mateus. Além dos fatores supracitados, contribuem para estes números as condições de conservação, pavimentação e sinalização das rodovias, assim como o aumento dos riscos devido ao relevo acidentado. Estes fatores aumentam a incidência dos acidentes nas estradas, fora das aglomerações urbanas, como é o caso da região de Cachoeiro de Itapemirim com elevada incidência de acidentes graves. Deve-se destacar, no caso de Guarapari, o aumento da população, do número de veículos e do tráfego nos meses de verão, quando o principal balneário do estado atrai um elevado número de turistas.

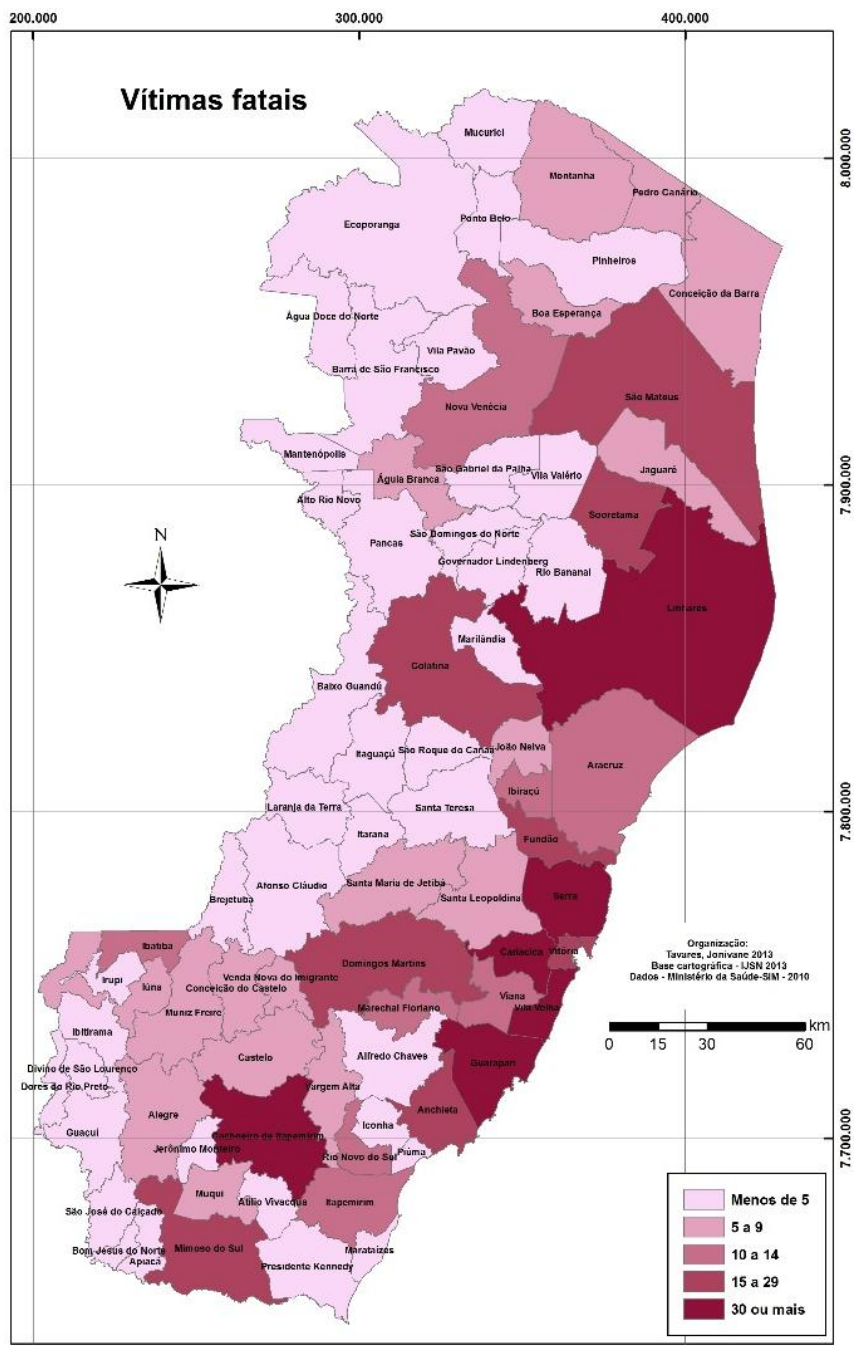

Figura 8: Distribuição das Vítimas fatais de acidentes - Espírito Santo - 2010 
Dados sobre os óbitos decorrentes de acidentes de trânsito são também fornecidos pelo SIM - Sistema de Informações sobre Mortalidade, do Ministério da Saúde, que publica anualmente os óbitos classificados segundo a Classificação Internacional de Doenças e Problemas Relacionados à Saúde CID-10. Nesta classificação, os óbitos por acidentes de trânsito compõem o Grupo de Causas Externas, que ocupa no Espírito Santo, o segundo posto no ranking das causas de mortalidade, superado somente pelo Grupo das Doenças do Aparelho Circulatório. A representação dos óbitos do grupo de Causas Externas ocorridos no Espírito Santo era de 18,8\% dos óbitos de 2010. Os dados de 2011 indicam uma redução da representação deste grupo para 17,9\% do total de óbitos.

No Grupo de Causas Externas, a categoria "acidentes de transporte terrestre" representa $28,9 \%$ dos óbitos do grupo em 2010, com ocorrência de 1.151 casos. As informações do Ministério da Saúde possibilitam a análise de alguns traços desta mortalidade, denominada a seguir como aparece nas estatísticas do SIM.

Os óbitos por acidentes de transportes terrestres ocorridos no Espírito Santo envolvem, com representações que quase se igualam, ocupantes de automóveis $(28,8 \%)$ e motociclistas $(28,3 \%)$, seguidos por pedestres $(20,0 \%)$.

O perfil das chamadas "mortes violentas" apresenta como traços marcantes a sobremortalidade masculina e a ocorrência de óbitos nas idades jovens. O forte grau de diferenciação por gênero destas causas é explicado pelos fatores culturais e comportamentais, que levam o homem a envolver-se, mais que as mulheres em situações perigosas e violentas e a exceder-se na velocidade no trânsito e no uso de bebidas alcoólicas, de drogas, de fumo (Figura 9). Entre 15 e 34 anos ocorrem 45,9 \% dos óbitos provocados por acidentes de transporte. A seletividade por gênero é traduzida pela razão de sexo, que foi de 453,3 mortes masculinas por 100 femininas em 2010. Esta relação atinge os valores de 532,0 para o grupo de 20 a 24 anos; 906,3 para o de 25 a 29 e 528,6 para o grupo de 30 a 34 anos. 


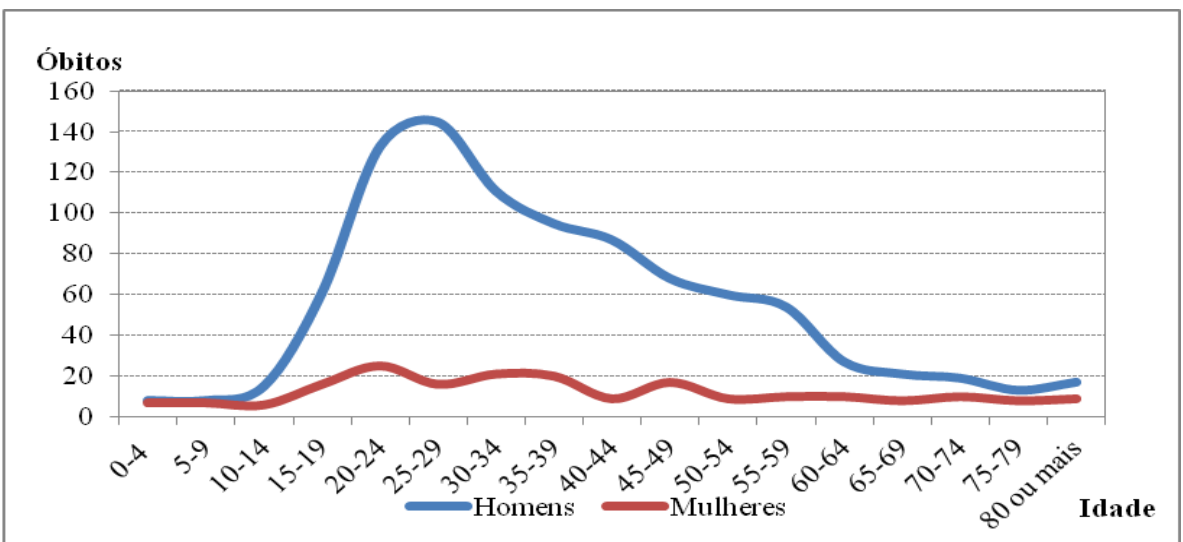

Figura 9: Óbitos por Acidentes de Transporte por ocorrência segundo o sexo e a faixa etária - Espírito Santo - 2010

Fonte. Elaborado com dados do Ministério da Saúde - SIM

\section{Inter-relações entre população, frota, acidentes e vítimas}

As variáveis abordadas neste estudo, relativas à população, frota, acidentes e vítimas apresentam forte correlação espacial como foi mostrado nos itens anteriores. Para sintetizar as relações entre as dimensões estudadas, o Método de Análise de Componentes Principais (ACP) foi aplicado à matriz contendo os valores de seis indicadores de população (população e densidade), frota, acidentes e vítimas (totais e fatais) para os 78 municípios do Espírito Santo em 2010. A ACP é um método de análise exploratória de dados que procede à redução de uma matriz de informações, possibilitando a análise e a explicação dos principais padrões de variabilidade de um conjunto multidimensional de dados. As relações entre as variáveis utilizadas são traduzidas por coeficientes de correlação linear que indicam fortes relações diretas entre essas variáveis. O método transforma as variáveis iniciais correlacionadas em novas variáveis, os fatores, conservando o máximo possível da variância e ao mesmo tempo limitando a redundância da informação (VOLLE, 1985; BLANXART, 1992; MINGOTI, 2005, JOHNSON; WICHERN, 2007).

Os dois primeiros fatores resultantes da aplicação da ACP contêm 98,3\% da informação total (Tabela 1). A matriz de dados é, assim, bem representada pelo primeiro fator, que sozinho condensa $89,7 \%$ da informação total, fornecendo uma síntese das 6 variáveis com as quais é forte e positivamente correlacionado (DUCHENE, WUNSCH, 1980). 
Tabela 1: Variância explicada pelos fatores

\begin{tabular}{c|c|c}
\hline Componentes & \% da variância & \% da variância acumulada \\
\hline 1 & 89,72 & 89,72 \\
2 & 8,59 & 98,31 \\
3 & 1,06 & 99,37 \\
4 & 0,43 & 99,80 \\
5 & 0,12 & 99,92 \\
6 & 0,08 & 100,00 \\
\hline
\end{tabular}

A tabela 2 apresenta as correlações existentes entre as variáveis iniciais e as variáveis construídas, os fatores, que podem ser interpretados a partir da significação das variáveis iniciais e do sentido positivo ou negativo das correlações.

Tabela 2: Coordenadas das variáveis nos dois primeiros fatores

\begin{tabular}{l|c|c}
\hline Variáveis & Fator 1 & Fator 2 \\
\hline V1. População & 0,974 & $-0,124$ \\
V2. Densidade & 0,867 & 0,487 \\
V3. Frota de Veículos & 0,994 & 0,023 \\
V4. Acidentes de trânsito & 0,981 & 0,167 \\
V5. Vítimas de acidentes de trânsito & 0,992 & $-0,075$ \\
V6. Óbitos por acidentes de transporte & 0,866 & $-0,478$ \\
\hline
\end{tabular}

A regionalização apresentada na Figura 10 foi feita a partir da contribuição dos municípios para a formação do fator 1 e do sentido desta relação. Os resultados da regionalização traduzem a diversidade do contexto analisado, traduzida por modelos distintos de representação dos processos focalizados. Os municípios com maiores escores positivos, que formam o Grupo 5, apresentam níveis elevados de concentração da população, da frota, dos acidentes e das vítimas. Este grupo é composto pelas principais municípios da RMGV: Vitória, Vila Velha, Serra e Cariacica. O segundo grupo, em ordem de contribuição de sentido positivo para a construção do fator 1 , Grupo 4 , é formado pelas principais cidades interioranas, Cachoeiro de Itapemirim e Colatina, cidades situadas no litoral norte, Linhares, São Mateus e Aracruz, e Guarapari e Viana da RMGV. O Grupo 3 apresenta valores intermediários para 
as variáveis, com exceção à ocorrência elevada de vítimas fatais de acidentes de trânsito, o grupo agrega cidades de porte médio e municípios da Região Serrana, com relevo acidentado. Os municípios que compõem os Grupos 1 e 2, que apresentam os menores escores sobre o fator 1, são situados em sua maioria nas regiões menos desenvolvidas, situadas majoritariamente no norte e oeste do Estado, com pequenas populações, baixas densidades, pequena frota e menores números de acidentes.

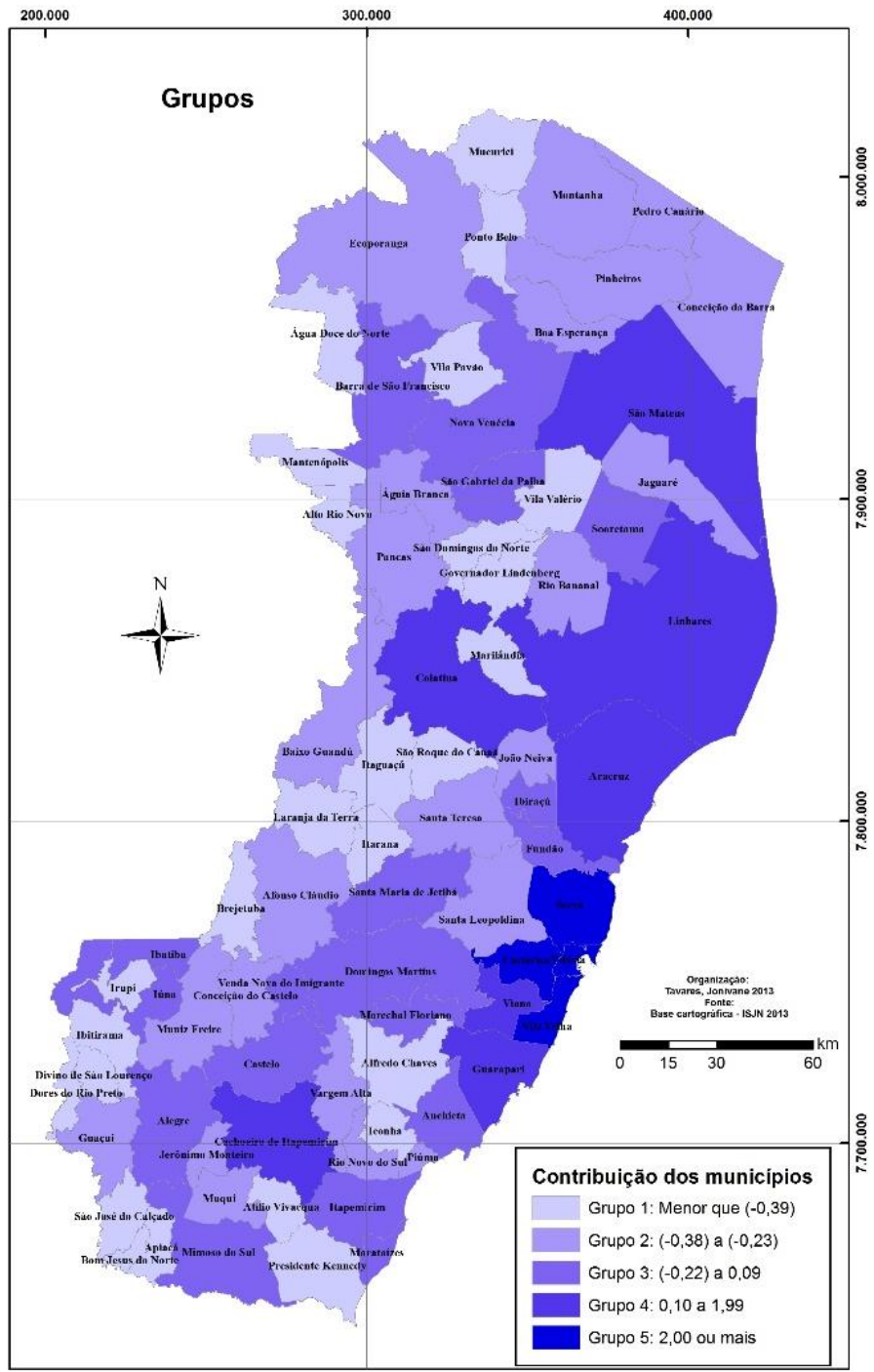

Figura 10: Contribuição dos Municípios do Espírito Santo para a formação do Fator 1 
A Tabela 3 apresenta os valores das variáveis analisadas calculados para os grupos formados à partir dos escores da $\mathrm{ACP}$.

Os grupos 1 e 2 apresentam características semelhantes: os dois conjuntos agregam 49 municípios, que correspondem à $62,8 \%$ do total. Caracterizam-se por serem as unidades menos populosas e as menos povoadas, os dois conjuntos congregam $20,2 \%$ da população do Estado e suas densidades demográficas, em torno de 29 a $30 \mathrm{hab} / \mathrm{km}^{2}$, são baixas comparativamente à densidade média do Estado, de $76,3 \mathrm{hab} / \mathrm{km}^{2}$. Os dois conjuntos apresentam pequenas frotas, as menores ocorrências de acidentes de trânsito, de vítimas de acidentes e de vítimas fatais. O Grupo 2 se destaca como o primeiro em extensão, ocupando $33,1 \%$ da superfície do Espírito Santo, enquanto que o grupo 1, formado por municípios menos extensos ocupa $19,1 \%$ da área do Estado. Os dois grupos se diferenciam quanto à relação entre as vítimas fatais de acidentes e a população: no Grupo 1 a taxa de mortalidade é a menor dentre os grupos, de 11,1 vítimas fatais por 100.000 habitantes, enquanto que, no Grupo 2, a taxa é de 25,1 por 100.000 , a segunda mais elevada dentre os grupos.

Tabela 3: Distribuição da população, área, frota, acidentes, vítimas e vítimas fatais por grupos

\begin{tabular}{c|c|c|c|c|c|c}
\hline Grupos & População & Área & $\begin{array}{r}\text { Frota de } \\
\text { veículos }\end{array}$ & $\begin{array}{c}\text { Acidentes } \\
\text { de trânsito }\end{array}$ & $\begin{array}{c}\text { Vítimas de } \\
\text { acidentes } \\
\text { de trânsito }\end{array}$ & $\begin{array}{c}\text { Vitimas } \\
\text { fatais de } \\
\text { acidente }\end{array}$ \\
\hline 1 & 7,47 & 19,09 & 8,25 & 3,46 & 5,64 & 4,28 \\
2 & 12,70 & 33,07 & 10,87 & 8,11 & 12,22 & 16,52 \\
3 & 14,27 & 22,65 & 14,81 & 11,85 & 17,01 & 26,11 \\
4 & 22,88 & 22,71 & 23,01 & 24,04 & 26,43 & 27,14 \\
5 & 42,69 & 2,47 & 43,06 & 52,52 & 38,71 & 25,96 \\
\hline Total & 100,00 & 100,00 & 100,00 & 100,00 & 100,00 & 100,00 \\
\hline
\end{tabular}

Fontes: Construídos com dados do IBGE, 2011 e do DETRAN-ES, 2011

O grupo 3, formado por 18 municípios, se caracteriza por seus valores intermediários. Ocupa a terceira posição na representação de todas as variáveis analisadas, com exceção da incidência de vítimas fatais, que o coloca no segundo posto, com 26,1\% do total de ocorrências do Espírito Santo, do que resulta a taxa de mortalidade mais elevada dentre os grupos, de 35,3 óbitos por 100.000 habitantes. 
O Grupo 4, o segundo em extensão, ocupando $22,7 \%$ da área do ES, é formado por 7 municípios. Este Grupo ocupa o segundo posto no ranking das variáveis demográficas (população: $22,9 \%$ do total; densidade: $76,8 \mathrm{hab} / \mathrm{km}^{2}$, próxima da média do Estado), no número de veículos (23,0\%), na ocorrência de acidentes $(24,0 \%)$ e no número de vítimas de acidentes de trânsito $(26,4 \%$ do total). $\mathrm{O}$ grupo 4 sobe para o primeiro posto quando se considera as vítimas fatais: os óbitos decorrentes de acidentes de trânsito ocorridos neste conjunto representaram 27,1\% dos óbitos ocorridos no Espírito Santo em 2010. O coeficiente de mortalidade igual a 22,9 vítimas fatais por 100.000 é mais elevado que a média do Estado $(19,3)$.

O Grupo 5, o mais diferenciado dos grupos formados, congrega apenas 4 municípios, todos situados na RMGV. Neste conjunto, que ocupa a menor área, de somente 2,5\% da superfície do Estado, vivem $42,7 \%$ da população total. A densidade elevada, de 1.316 é indicativa do adensamento da população desta região. A concentração da população e das atividades econômicas, dos bens e serviços faz desta região a mais dinâmica do Estado. Segundo os dados de 2010 , neste grupo se concentra a maior parte da frota, que representa $43,1 \%$ do total do estado, como também mais da metade dos acidentes $(52,5 \%)$. Nas vias deste grupo ocorre a maior parte dos acidentes com vítimas, 38,7\% do total, no entanto, a ocorrência de vítimas fatais é a segunda em número de casos $(26,0 \%)$ ultrapassada pelos números do Grupo 4. Considerando a população elevada deste grupo, o coeficiente de mortalidade apresenta o segundo valor mais baixo, de 11,7 óbitos fatais por 100.000 habitantes.

A análise da ocorrência de acidentes com vítimas mostrou valores mais baixos nos Grupos extensos e pouco populosos, os valores se elevam nas maiores aglomerações urbanas.

A análise da representação dos tipos de veículos envolvidos em acidentes com vítimas ocorridos nos cinco grupos no total de acidentes do Estado coloca em evidência que: (1) os grupos 1 e 2, extensos e pouco populosos apresentam valores mais elevados para a ocorrência de acidentes com vítimas envolvendo motocicletas e caminhões; (2) O grupo 3 formado por municípios situados na região serrana, de relevo acidentado, diferencia-se pelos valores elevados de acidentes envolvendo caminhões (26,5\% do total do ES); (3) nos grupos mais urbanizados, 4 e 5, a composição dos acidentes reflete a intensidade e as tensões do trânsito nos maiores aglomerados urbanos, no Grupo 4 os acidentes envolvendo bicicletas, automóveis e motos apresentam as maiores representações enquanto que no grupo 5 destacam-se os acidentes com ônibus e micro-ônibus, caminhonetes, bicicletas e automóveis.

A distribuição dos tipos de vítimas de acidentes de trânsito segundo os grupos formados com os fatores extraídos da ACP mostra que nos grupos 
menos urbanizados há incidência maior de acidentes que ocorrem nas estradas, envolvendo passageiros, caminhoneiros e motociclistas, o grupo 3 é o que apresenta a maior representação de caminhoneiros envolvidos em acidentes: 40,1\% do total do Estado. Nos grupos mais urbanizados preponderam acidentes envolvendo pedestres, ciclistas e motociclistas, mais frequentes no trânsito urbano.

\section{Considerações finais}

O incremento da população e da frota ocorridos durante a segunda metade do século $\mathrm{XX}$ e início do século atual mudaram o cenário e as condições do trânsito no país, em particular nas áreas mais urbanizadas. A expansão e a modernização da infraestrutura de transporte não acompanharam crescimento demográfico e da frota, produzindo como consequências o caos do tráfego nas vias mais movimentadas e o aumento de acidentes e de vítimas de acidentes em todo o território. O cenário do trânsito nas últimas décadas registra a presença crescente de motocicletas, sem que tenha havido adequação para esta nova demanda de infraestrutura. Além dos acidentes, focalizados neste trabalho, as condições do cenário atual do trânsito produzem efeitos negativos em várias esferas, como o aumento do custo do transporte, das horas de deslocamento e do stress da população, a perda de horas produtivas do trabalhador.

O Espírito Santo apresenta um cenário alinhado com a tendência nacional. A passagem de uma sociedade tradicional, voltada para o meio rural e para a cultura do café, para uma sociedade moderna, com foco nas atividades urbanas, industriais, comerciais e de serviços, é marcada pelo adensamento demográfico, pelo incremento dos transportes, e pelo agravamento das condições do tráfego.

Com esperado, os resultados do trabalho mostraram que a distribuição espacial dos acidentes com vítimas e dos acidentes com vítimas fatais no Espírito Santo em 2010 apresenta relações com o adensamento da população e o tamanho da frota. O número de vítimas de acidentes é maior nos municípios mais populosos e com maiores frotas da Região Metropolitana da Grande Vitória e dos principais centros urbanos situados fora da região da capital. As regiões menos povoadas, situadas majoritariamente no norte e do oeste do estado apresentam frotas menos importantes e menos ocorrência de acidentes.

Dentre os resultados da análise pode-se destacar o crescimento dos acidentes em geral, e, em particular o envolvimento crescente de motocicletas em acidentes com vítimas. De 2005 a 2010 o número de veículos que sofreram acidentes com vítimas teve um aumento de 50,3\%, porém os acidentes 
envolvendo motocicletas quase dobraram nesse período, apresentando um crescimento de 98,8\%. Deve-se destacar também a importância da seletividade dos acidentes quanto ao gênero e à idade das vítimas.

$\mathrm{O}$ método aplicado à matriz de dados, a Análise de Componentes Principais (ACP) possibilitou primeiramente a redução da informação: o primeiro fator formado fornece uma síntese das variáveis que representam a população, frota e os acidentes. Os resultados da ACP foram utilizados para formar grupos de municípios que apresentam comportamentos similares relativos às variáveis analisadas. Os cinco grupos formados situam-se numa escala que se estende dos baixos aos altos níveis de adensamento demográfico, da frota e da incidência de acidentes. Nesta escala, os grupos mais urbanizados, próximos à Região da Capital se opõem aos grupos situados em áreas menos desenvolvidas do Estado, com pequenas populações e baixas densidades, pequena frota e menores números de acidentes.

Os problemas relativos ao trânsito no Espírito Santo estão relacionados à defasagem na ampliação e na modernização da infraestrutura de transportes: insuficiência da rede viária, qualidade precária das vias existentes, falta de conservação e sinalização das rodovias, violência no trânsito, falta de fiscalização, da falta de transportes coletivos. Na região de relevo acidentado, este fator aumenta os riscos de acidentes, fato colocado em evidência na análise dos dados. Acrescente-se que a falta de educação para o trânsito, assim como a capacidade profissional do condutor contribuem para o agravamento do cenário do trânsito.

A Assembleia Geral das Nações Unidas instituiu o ano 2011 como o início da "Década de Ação para a Segurança no Trânsito", campanha mundial para reduzir a violência no trânsito. A campanha tem como meta reduzir pela metade o número de vítimas de acidentes de trânsito até 2020 (EMPRESA BRASIL DE COMUNIÇÃO, acesso em 12/12/2013). Para alcançar a meta os Ministérios da Saúde e das Cidades lançaram em 2011 o Pacto Nacional pela Redução dos Acidentes de Trânsito - Pacto pela Vida. Este grande desafio não logrará êxito sem a efetivação de ações concretas para modernização da infraestrutura do trânsito e para a educação da população.

A modificação dos padrões demográficos, de consumo e de utilização dos meios de transporte traduzem conquistas sociais, mas trazem em seu bojo problemas de difícil solução nas sociedades dos países em desenvolvimento. As análises efetuadas mostram as correlações existentes entre os processos analisados, apontando problemas e possíveis tendências que requerem a atenção especial do governo e o envolvimento de todos os setores sociedade da sociedade para a reversão do grave cenário atual do trânsito. 


\section{Referências}

AGÊNCIA CNT DE NOTÍCIAS. Total de indenizações pagas pelo DPVAT em 2013 cresceu 25\%.12/02/2014.Disponível em:

http://www.cnt.org.br/paginas/Agencia_Noticia.aspx?noticia=dpvat-segurosindenizacoes-acidentes-transito-vitimas-como-solicitar-seguradora-lider12022014/ Acesso em: 14/02/2014.

ALVES, P.; RAIA JUNIOR, Archimedes A. Análise de correlação entre acidentes de trânsito, uso e ocupação do solo, polos geradores de viagens e população em Uberlândia-MG. Revista dos Transportes Públicos, v. 130, p. 55-70, 2012. Disponível em: http://issuu.com/efzy/docs/rtp2012-130-00/ Acesso em 12/12/2013.

BLANXART, Monserrat Freixa et al. Análisis exploratorio de datos: nuevas técnicas estadísticas, Barcelona:Promociones y Publicationes Universitarias, 1992.

CASTIGLIONI, A.H. ; FAÉ, M.I. Interrelation of vehicle production, population rate and traffic casualties in Brazilian cities. In: ICIL 2012 -

International Conference on Industrial Logistics, 2012, Zadar. ICIL 2012. Conference Proceedings. Zagreb: FSB, 2012. v. 1. p. 182-189.

CASTIGLIONI, A.H.. Mudanças na estrutura demográfica do Espírito Santo ocorridas durante a segunda metade do século XX. Geografares (Vitória), v. 7, p. 93-109, 2009. Disponível em:

file://C:/Users/Aurelia\%20Castiglioni/Downloads/153-85-1-PB\%20(1).pdf. Acesso em: 10/12/2013.

DETRAN-ES. Acidentes de trânsito 2005-2009. Disponível em: http://www.detran.es.gov.br/default.asp/. Acesso em: 10/12/2013.

DETRAN-ES. ANUÁRIO DETRAN-ES 2010, DETRAN-ES, 2011.

DNIT - Departamento Nacional de Infraestrutura de Transportes; DPRF Departamento de Polícia Rodoviária Federal. Anuário Estatístico das

Rodovias Federais 2010, Brasília, 2010. Disponível em: http://www.dnit.gov.br/rodovias/operacoes-rodoviarias/estatisticas-deacidentes/anuario-2010.pdf. Acesso em: 15/12/2013.

DUCHENE, Josianne et WUNSCH, Guillaume. Population-type optimale et composante principale, Population et Famille, 49, p 23-30, 1980.

EMPRESA BRASIL DE COMUNICAÇÃO. Agência Brasil. Brasil lança pacto pela redução dos acidentes de trânsito. 11/05/2011. Disponível em: http://agenciabrasil.ebc.com.br/noticia/2011-05-11/brasil-lanca-pacto-pelareducao-dos-acidentes-de-transito/. Acesso em: 12/12/2013. 
IBGE - Conselho Nacional de Estatística. Censo Demográfico 1950, RJ: IBGE, 1955.

IBGE - Instituto Brasileiro de Geografia e Estatística. Censo demográfico 2000, RJ:IBGE.

IBGE. Fundação Instituto Brasileiro de Geografia e Estatística. Resultados do Censo 2010, 2011. Disponível em: http://www.sidra.ibge.gov.br/. Acesso em : $15 / 11 / 2013$.

JOHNSON, R. A.; WICHERN, D. W. Applied Multivariate Statistical Analysis.New Jersey: Pearson, 2007.

LANDRY, A. La révolution démographique - Études et essais sur les problèmes de la population. Paris: INED - Presses Universitaires de France, 1982 [1934].

MINGOTI, S. A. Análise de Dados através de Métodos de Estatística Multivariada: uma abordagem aplicada. Belo Horizonte: Editora UFMG, 2005.

MINISTÉRIO DAS CIDADES. DENATRAN-Departamento Nacional de Trânsito. Frota 2000-2013. Disponível em:

http://www.denatran.gov.br/frota.htm/ Acessos em 05/12/2013 e em 03/02/2014.

MINISTÉRIO DA SAÚDE. Sistema de informações sobre mortalidade - SIM. Disponível em:

http://www2.datasus.gov.br/DATASUS/index.php?area=0205\&VObj=http://ta bnet.datasus.gov.br/cgi/deftohtm.exe?sim/cnv/obt10/. Acesso em: 08/12/2013.

PATARRA, N.L.; FERREIRA, C.E. Repensando a transição demográfica: formulações, críticas e perspectivas de análise. Campinas:

NEPO/UNICAMP. 1996.

SCHRAMM, J. M. A.; OLIVEIRA, A.F.; LEITE, I.C.; VALENTE, J.G.;

GADELHA, A.M.J.; PORTELA, M.C.; CAMPOS, M.R. Transição epidemiológica e o estudo de carga de doença no Brasil. Ciência \& Saúde Coletiva, v.9, n. 4, p. 897-908, 2004.

VASCONCELLOS, E. A.; CARVALHO, C. H. R. de; PEREIRA, R. H. M. Transporte e mobilidade urbana. Textos para Discussão CEPAL-IPEA, 34. Brasília, DF: CEPAL. Escritório no Brasil, 2011.

VOLLE, M. Analyse des données, Paris:Economica, 1985. 


\section{Aurélia H. Castiglioni}

Mestre e Doutora em Demografia pela Université Catholique de Louvain, Bélgica.

Professora do Depto de Geografia e dos Programas de Pós-Graduação em Geografia e Economia da Universidade Federal do Espírito Santo.

Rua Chapot Presvot 119, apto 602

29.055-410 - Vitória - ES

E-mail: aurelia.castiglioni@gmail.com

\section{Maria Inês Faé}

Engenheira Civil, Mestre e Doutora em Transportes. Professora do Programa de PósGraduação em Geografia da Universidade Federal do Espírito Santo. Avaliadora do Instituto Nacional de Estudos e Pesquisas Educacionais. Rua José Malta, 380, Fradinhos, 29042-480, Vitória, ES

E-mail: mariafae@gmail.com

Recebido para publicação em dezembro de 2013 Aprovado para publicação em fevereiro de 2014 